\title{
A FAMÍLIA NO CUIDADO DE ENFERMAGEM À CRIANÇA: REVISÃO INTEGRATIVA
}

\author{
Aline Rigo Estevão ${ }^{1}$, Fernanda Cassanho Teodoro ${ }^{2}$, Magda Nanuck Ribas Pinto ${ }^{3}$, Márcia Helena de Souza \\ Freire ${ }^{4}$, Verônica de Azevedo Mazza ${ }^{5}$
}

RESUMO: Este estudo objetivou investigar a produção científica sobre o cuidado de enfermagem à criança com enfoque na família. Trata-se de uma revisão integrativa realizada em cinco bases de dados, no mês de junho de 2016. Os critérios de inclusão foram: publicações científicas divulgadas entre 2010 a 2015, no formato de artigo científico, nos idiomas inglês, português e espanhol, e de livre acesso. A amostra foi composta por 16 artigos, dos quais emergiram duas categorias temáticas: reconhecimento da unidade familiar; limitações para o cuidado à criança com enfoque na família.O cuidado à criança com enfoque na família valoriza a participação dos familiares na sua execução, favorece o vínculo profissional-família com reconhecimento do cuidado contínuo, e evidencia as peculiaridades de cada família.

DESCRITORES: Cuidado da criança; Família; Enfermagem; Enfermagem familiar; Cuidador.

\section{THE FAMILY IN NURSING CARE FOR CHILDREN: AN INTEGRATIVE REVIEW}

ABSTRACT: This study aimed to investigate the scientific production on nursing care for children with a family focus. An integrative review was undertaken in five databases in June 2016. The inclusion criteria were: scientific publications disseminated between 2010 and 2015, in the form of a scientific article, in English, Portuguese and Spanish, and available through open access. The sample consisted of 16 articles, from which two thematic categories emerged: recognition of the family unit; limitations for childcare with a family focus. Childcare with a family focus values the relatives' participation in its execution, favors the professional-family bond with recognition of continuing care, and evidences the peculiarities of each family.

DESCRIPTORS: Childcare; Family; Nursing; Family nursing; Caregiver.

\section{EL PAPEL DE LA FAMILIA EN EL CUIDADO DE ENFERMERÍA AL NIÑO: REVISIÓN INTEGRATIVA}

RESUMEN: Este estudio tuvo la finalidad de investigar la producción científica acerca de cuidado de enfermería al niño enfocándose el papel de la familia. Es una revisión integrativa realizada en cinco bases de datos, en el mes de junio de 2016. Los criterios de inclusión fueron: publicações científicas divulgadas entre 2010 y 2015, en forma de artículo científico, en los idiomas inglés, portugués y español, y de libre acceso. La muestra se compuso por 16 artículos, de los cuales resultaron dos categorías temáticas: reconocimiento de la unidad familiar; limitaciones para el cuidado al niño con enfoque en la familia. El cuidado al niño con enfoque en la familia valora la participación de los familiares en su ejecución, favorece el vínculo profesional-familia con reconocimiento del cuidado continuo, además de evidenciar las peculiaridades de cada familia.

DESCRIPTORES: Cuidado del niño; Familia; Enfermería; Enfermería familiar; Cuidador.

${ }^{1}$ Enfermeira. Prefeitura Municipal de Morretes. Universidade Federal do Paraná. Curitiba, PR, Brasil.

Enfermeira. Doutoranda em Enfermagem. Universidade Federal do Paraná. Curitiba, PR, Brasil.

${ }^{3}$ Enfermeira. Mestre em Educação. Docente de Enfermagem da Universidade Federal do Paraná. Curitiba, PR, Brasil.

${ }^{4}$ Enfermeira. Doutora em Saúde Pública. Docente de Enfermagem da Universidade Federal do Paraná. Curitiba, PR, Brasil.

${ }^{5}$ Enfermeira. Doutora em Enfermagem. Docente de Enfermagem da Universidade Federal do Paraná. Curitiba, PR, Brasil. 


\section{INTRODUÇÃO}

Sob a ótica legal e biopsicossocial, a criança é um ser vulnerável que requer cuidado e observação meticulosa, em especial, no convívio sócio-familiar. No cuidado à criança deve ser considerada a possibilidade de exposição a fatores deletérios ao seu crescimento e desenvolvimento e o risco de adoecimento próprio deste ciclo vital. Estas situações adversas podem acarretar sofrimento ou modificações nas formas de organização da família ${ }^{(1-2)}$.

A família é um sistema complexo constituído por indivíduos que, em suas peculiaridades, mantêm relações e ligações com valores insubstituíveis. Assim, quando um ente adoece ou morre, outro membroassume as atividades as quais eram desenvolvidas por aquele ${ }^{(3)}$. Neste contexto, quando a família sofre mudanças abruptas, como adoecimento e/ou hospitalização da criança, precisa se reordenar para lidar com a nova dinamicidade imposta pela situação ${ }^{(4)}$. Portanto, ela precisará lançar de subterfúgios para lidar com adoecimento infantil e todas as consequências deste processo ${ }^{(1,3,5)}$.

O adoecimento e a hospitalização são carreados de tristeza e estresse, pois, neste momento, o familiar/acompanhante sofre com o adoecimento, seja pela própria condição de saúde ou por internar-se, deixando em segundo plano os compromissos domésticos e profissionais ${ }^{(6)}$. Sendo assim, o cuidado de enfermagem deve concernir na pluralidade, atender a criança e prestar apoio ao familiar /acompanhante ${ }^{(4)}$.

Destarte, o olhar atencioso e o reconhecimento da família como elemento no cuidado à criança são imprescindíveis para promover a saúde infantil e familiar. Para isto, este estudo propõe investigar a produção científica sobre o cuidado de enfermagem à criança com enfoque na família.

\section{MÉTODO}

Trata-se de um estudo de revisão integrativa da literatura sobre o cuidado à criança com enfoque na família. Nesta revisão seguiram-se as seguintes etapas: elaboração da questão norteadora, busca na literatura segundo critérios de exclusão e inclusão, extração de dados dos artigos selecionados, análise dos dados encontrados, interpretação dos resultados e apresentação da revisão ${ }^{(7)}$.

Elaborou-se a questão norteadora "Qual a contribuição da produção científica acerca do cuidado de enfermagem à criança com enfoque na família?". Na busca dos artigos, utilizaram-se os seguintes descritores e palavras-chave: família (family/familia), criança (child/niño), cuidados de enfermagem (nursing care/atención de enfermería), enfermagem (nursing/enfermería) e cuidado da criança (child care/cuidado del niño). Utilizou-se as bases de dados eletrônicas: Medical Literature Analysis and Retrieval System Online (MEDLINE), Literatura Latino Americano em Ciências da Saúde (LILACS), PubMED, Bases de Dados em Enfermagem (BDENF) e Scientific Eletronic Library Online (SciELO).

A busca foi realizada no mês de junho de 2016. Para a seleção dos artigos, foram estabelecidos os critérios de inclusão: artigos originais e atuais publicados nos últimos cinco anos, isto é, no período de 2010 a 2015; nos idiomas português, inglês e espanhol; com disponibilidade do texto na íntegra on-line e gratuitamente, e com resumo. Foram excluídos os artigos que não respondiam à questão norteadora, os repetidos nas bases de dados, e os textos com acesso restrito.

A seleção dos estudos procedeu-se em três fases: 1) exclusão das publicações repetidas nas bases de dados; 2) leitura do título e do resumo das publicações, com exclusão daquelas que não atendiam a questão norteadora desta revisão; 3) avaliação crítica dos artigos mediante a leitura na íntegra, seguida da elaboração de quadros sinópticos com os dados coletados.

Para a análise, os artigos foram lidos crítica e exaustivamente, sendo categorizados em temáticas que

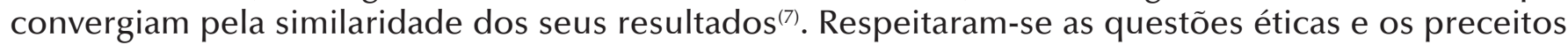
de autoria, sendo que os artigos consultados foram citados e referenciados ao longo deste estudo.

\section{RESULTADOS}


Realizada a busca, conforme os critérios estabelecidos, a amostra foi representada por 16 artigos. Na Figura 1 apresenta-se o fluxograma de busca e coleta de dados, proposto por Preferred Reporting Items for Systematic Reviews and Meta-Analyses-PRISM(8). Embora a revisão integrativa não tenha um esquema gráfico de procedimento, este estudo optou pelo uso da ferramenta supracitada, para esboçar a trajetória da seleção de artigos. Foram localizados 1751 artigos utilizando-se os descritores ou palavras-chave, sem considerar o tema família no título. Foram 164 publicações que estavam duplicadas nas bases de dados, restando 1417 publicações (Figura 1).
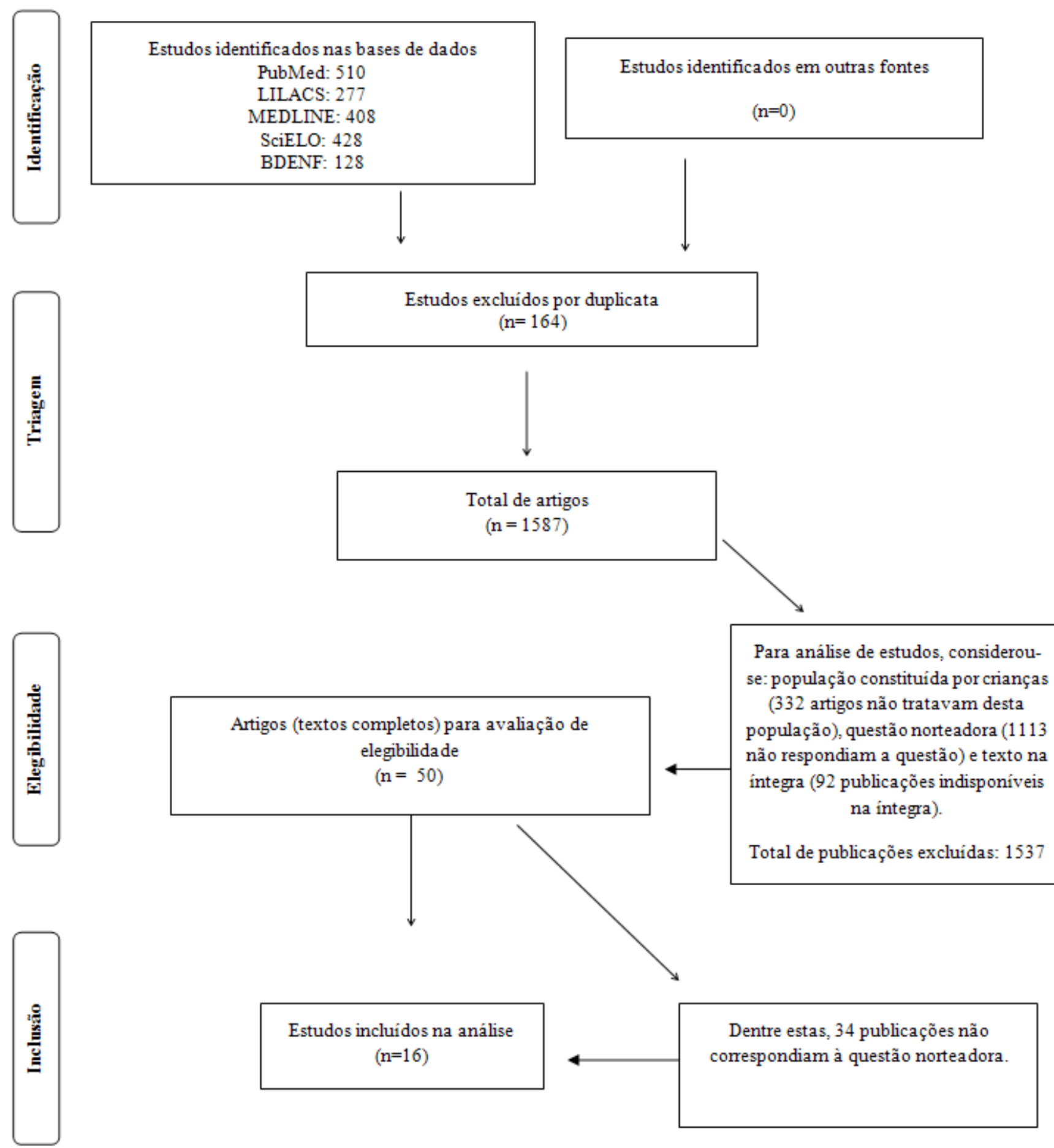

Figura 1 - Fluxograma da coleta de dados. Curitiba, 2016

Dos artigos incluídos, cinco (38,5\%) foram publicados em 2012, e no ano de 2013 não houve publicação (Quadro 1). Treze artigos (81\%) estavam indexados na base de dados SciELO. 
Quadro 1 - Relação de artigos inclusos no estudo. Curitiba, 2016

\begin{tabular}{|c|c|c|c|c|c|}
\hline $\begin{array}{l}\text { Ordem } \\
\text { numérica }\end{array}$ & Título & Autores & Ano & Revista & $\begin{array}{c}\text { Base de } \\
\text { dados }\end{array}$ \\
\hline 1 & $\begin{array}{c}\text { Relações estabelecidas pelas } \\
\text { enfermeiras com a família durante a } \\
\text { hospitalização infantil }\end{array}$ & $\begin{array}{c}\text { de Lima AS, da Silva } \\
\text { VKBA, Collet N, Reichert } \\
\text { APS, de Oliveira BRG }\end{array}$ & 2010 & $\begin{array}{l}\text { Texto } \\
\text { Contexto } \\
\text { Enferm. }\end{array}$ & SciELO \\
\hline 2 & $\begin{array}{l}\text { Cuidado centrado na família e sua } \\
\text { aplicação na enfermagem pediátrica }\end{array}$ & $\begin{array}{c}\text { Pinto JP, Ribeiro CA, } \\
\text { Pettengill M M, Balieiro } \\
\text { MMFG }\end{array}$ & 2010 & $\begin{array}{l}\text { Rev. bras. } \\
\text { enferm. }\end{array}$ & SciELO \\
\hline 3 & $\begin{array}{l}\text { Interação familiar/acompanhante e } \\
\text { equipe de enfermagem no cuidado } \\
\text { à criança hospitalizada: perspectivas } \\
\text { para a enfermagem pediátrica }{ }^{(1)}\end{array}$ & $\begin{array}{c}\text { de Souza, TV, Oliveira, } \\
\text { ICS }\end{array}$ & 2010 & $\begin{array}{l}\text { Esc. Anna } \\
\quad \text { Nery }\end{array}$ & SciELO \\
\hline 4 & $\begin{array}{l}\text { Típico da ação do profissional de } \\
\text { enfermagem quanto ao cuidado } \\
\text { familial da criança hospitalizada }^{(10)}\end{array}$ & $\begin{array}{c}\text { Rossi CS, Rodrigues } \\
\text { BMRD }\end{array}$ & 2010 & $\begin{array}{l}\text { Acta paul. } \\
\text { enferm }\end{array}$ & SciELO \\
\hline 5 & $\begin{array}{l}\text { A família na unidade de pediatria: } \\
\text { percepções da equipe de enfermagem } \\
\text { acerca da dimensão cuidadora }{ }^{(2)}\end{array}$ & $\begin{array}{c}\text { de Sousa LD, Gomes GC, } \\
\text { da Silva MRS, dos Santos } \\
\text { CP, da Silva BT }\end{array}$ & 2011 & $\begin{array}{l}\text { Cienc. } \\
\text { enferm. }\end{array}$ & SciELO \\
\hline 6 & $\begin{array}{c}\text { Promoção do cuidado humanizado à } \\
\text { família pela equipe de enfermagem na } \\
\text { unidade neonatal }{ }^{(11)}\end{array}$ & $\begin{array}{l}\text { Rocha RS, Lúcio IML, } \\
\text { Lopes MMCO, Lima } \\
\text { CRC, Freitas ASF }\end{array}$ & 2011 & Rev. Rene & PubMed \\
\hline 7 & $\begin{array}{c}\text { Importância da relação interpessoal do } \\
\text { enfermeiro com a família de crianças } \\
\text { hospitalizadas }^{(12)}\end{array}$ & $\begin{array}{c}\text { Murakami R, Campos } \\
\text { CJG }\end{array}$ & 2011 & $\begin{array}{l}\text { Rev.bras. } \\
\text { enferm. }\end{array}$ & PubMed \\
\hline 8 & $\begin{array}{l}\text { Cuidados Centrados na Família: } \\
\text { impacto da formação e de um manual } \\
\text { de boas práticas em pediatria }{ }^{(13)}\end{array}$ & Apolinário MICG & 2012 & Rev Enf Ref. & SciELO \\
\hline 9 & $\begin{array}{l}\text { Acompañamiento familiar en la } \\
\text { hospitalización del usuario pediátrico de } \\
6 \text { a } 12 \text { años }^{(14)}\end{array}$ & $\begin{array}{c}\text { Astudillo AA, Martínez } \\
\text { MA, Muñoz BC, Pacheco } \\
\text { LM, Sepúlveda GA }\end{array}$ & 2012 & $\begin{array}{l}\text { Cienc. } \\
\text { enferm. }\end{array}$ & SciELO \\
\hline 10 & $\begin{array}{c}\text { Cuidado centrado na família no } \\
\text { contexto da criança com } \\
\text { deficiência e sua família: uma análise } \\
\text { reflexiva(15) }^{(15)}\end{array}$ & $\begin{array}{l}\text { Barbosa MAM, Balieiro } \\
\text { MMFG, Pettengill MAM }\end{array}$ & 2012 & $\begin{array}{l}\text { Texto } \\
\text { Contexto } \\
\text { Enferm. }\end{array}$ & SciELO \\
\hline 11 & $\begin{array}{c}\text { A rede social de crianças com } \\
\text { necessidades especiais de saúde } \\
\text { na (in) visibilidade do cuidado de } \\
\text { enfermagem } \\
\text { ent) }\end{array}$ & $\begin{array}{l}\text { de Moraes JRM, Cabral } \\
\text { IE }\end{array}$ & 2012 & $\begin{array}{l}\text { Rev. } \\
\text { Latino-Am. } \\
\text { Enfermagem }\end{array}$ & SciELO \\
\hline 12 & $\begin{array}{l}\text { Qualificando o cuidado a criança na } \\
\text { atenção primária de saúde } \\
\end{array}$ & $\begin{array}{l}\text { de Sousa FGM, Erdmann } \\
\text { AL }\end{array}$ & 2012 & $\begin{array}{l}\text { Rev.bras. } \\
\text { enferm. }\end{array}$ & SciELO \\
\hline 13 & $\begin{array}{l}\text { Envolvimento dos pais nos cuidados } \\
\text { de saúde de crianças hospitalizadas }{ }^{(18)}\end{array}$ & $\begin{array}{c}\text { de Melo EMOP, Ferreira } \\
\text { PL, de Lima RAG, de } \\
\text { Mello DF }\end{array}$ & 2014 & $\begin{array}{l}\text { Rev. } \\
\text { Latino-Am. } \\
\text { Enfermagem }\end{array}$ & SciELO \\
\hline 14 & $\begin{array}{l}\text { As práticas do Cuidado Centrado na } \\
\text { Família na perspectiva do enfermeiro } \\
\text { da Unidade Neonatal }{ }^{(19)}\end{array}$ & $\begin{array}{c}\text { Corrêa AR, Andrade AC, } \\
\text { Manzo BF, Couto DL, } \\
\text { Duarte ED }\end{array}$ & 2015 & $\begin{array}{l}\text { Esc. Anna } \\
\text { Nery }\end{array}$ & SciELO \\
\hline 15 & $\begin{array}{l}\text { Uso da narrativa como estratégia } \\
\text { de sensibilização para o modelo do } \\
\text { cuidado centrado na família(20) }\end{array}$ & $\begin{array}{c}\text { Amador DD, Marques } \\
\text { FRB, Duarte AM, Balbino } \\
\text { FS, Balieiro MMFG, } \\
\text { Mandetta MA }\end{array}$ & 2015 & $\begin{array}{l}\text { Rev. Gaúcha } \\
\text { Enferm. }\end{array}$ & SciELO \\
\hline 16 & $\begin{array}{c}\text { Recommendations for involving the } \\
\text { family in developmental care of the NICU } \\
\qquad \text { baby }^{(21)}\end{array}$ & $\begin{array}{c}\text { Craig JW, Glick C, } \\
\text { Phillips R, Hall SL, Smith } \\
\text { J, Browne J }\end{array}$ & 2015 & J Perinatol. & PubMed \\
\hline
\end{tabular}


Em relação à abordagem da pesquisa, 11 (69\%) foram qualitativas, dois (12,5\%) quantitativas e duas (12,5\%) reflexões (Quadro 2). Três publicações explicitavam o referencial teórico (19\%), e uma o modelo teórico do Cuidado Centrado na Família; enquanto que sete delas (44\%) mencionavam o referencial metodológico (Quadro 2).

Quadro 2 - Objetivo e metodologia das publicações selecionadas. Curitiba, Paraná, Brasil, 2016

\begin{tabular}{|c|c|c|}
\hline $\begin{array}{l}\text { Ordem } \\
\text { numérica }\end{array}$ & Objetivo & Metodologia \\
\hline 1 & $\begin{array}{l}\text { Analisar as relações entre enfermeiros e familiares } \\
\text { de crianças hospitalizadas }^{(9)}\end{array}$ & $\begin{array}{l}\text { Pesquisa qualitativa do tipo descritivo-exploratória } \\
\text { realizada em uma unidade de internação pediátrica }\end{array}$ \\
\hline 2 & $\begin{array}{l}\text { Refletir acerca da unidade familiar no cuidado ao } \\
\text { indivíduo e família }^{(5)}\end{array}$ & Reflexão sob a ótica da Teoria Geral dos Sistemas \\
\hline 3 & $\begin{array}{l}\text { Descrever os cuidados prestados pelo familiar/ } \\
\text { acompanhante e pela equipe de enfermagem } \\
\text { à criança durante a hospitalização. Além disso, } \\
\text { objetivou-se analisar as estratégias implementadas } \\
\text { entre familiar/profissional para o cuidado à criança } \\
\text { hospitalizada }^{(1)}\end{array}$ & $\begin{array}{l}\text { Pesquisa qualitativa do tipo estudo de caso, realizada } \\
\text { sob a ótica antropológica de cultura }\end{array}$ \\
\hline 4 & $\begin{array}{l}\text { Analisar o cuidado de enfermagem à família em } \\
\text { unidade pediátrica }^{(10)}\end{array}$ & $\begin{array}{l}\text { Estudo descritivo qualitativo, analisado a partir da } \\
\text { fenomenologia sociológica de Alfred Schutz }\end{array}$ \\
\hline 5 & $\begin{array}{l}\text { Analisar o significado do cuidado à família para a } \\
\text { equipe de enfermagem }{ }^{(2)}\end{array}$ & $\begin{array}{l}\text { Estudo qualitativo realizado em uma unidade de } \\
\text { pediatria de um hospital universitário. A pesquisa foi } \\
\text { conduzida a partir da Hermenêutica-dialética }\end{array}$ \\
\hline 6 & $\begin{array}{l}\text { Conhecer a percepção da equipe de enfermagem } \\
\text { sobre humanização no cuidado à família de recém- } \\
\text { nascidos hospitalizados em unidade neonatal }{ }^{(11)}\end{array}$ & $\begin{array}{l}\text { Estudo descritivo com abordagem qualitativa } \\
\text { realizado em uma unidade de internação neonatal } \\
\text { de uma maternidade pública }\end{array}$ \\
\hline 7 & $\begin{array}{l}\text { Avaliar a relação interpessoal enfermeiro e familiar } \\
\text { da criança hospitalizada }{ }^{(12)}\end{array}$ & $\begin{array}{l}\text { Pesquisa clínico-qualitativa realizada em um hospital } \\
\text { público }\end{array}$ \\
\hline 8 & $\begin{array}{l}\text { Avaliar o conhecimento e a percepção dos } \\
\text { enfermeiros acerca dos cuidados centrados na } \\
{\text { família aplicados na pediatria }{ }^{(13)}}\end{array}$ & $\begin{array}{l}\text { Estudo quase experimental, do tipo pré e pós-teste } \\
\text { sem grupo controle, com abordagem quantitativa }\end{array}$ \\
\hline 9 & $\begin{array}{l}\text { Descrever o acompanhamento familiar durante a } \\
\text { hospitalização de crianças de } 6-12 \text { anos }^{(14)}\end{array}$ & $\begin{array}{l}\text { Estudo descritivo corte transversal com abordagem } \\
\text { quantitativa, realizado em uma instituição chilena }\end{array}$ \\
\hline 10 & $\begin{array}{l}\text { Refletir acerca do trabalho da equipe de saúde no } \\
\text { cuidado à família de crianças deficientes }{ }^{(15)}\end{array}$ & $\begin{array}{l}\text { Reflexão embasada na revisão de literatura à luz dos } \\
\text { pressupostos do Cuidado Centrado na Família }\end{array}$ \\
\hline 11 & $\begin{array}{l}\text { Identificar o cuidado de enfermagem à família } \\
\text { na rede social de crianças com necessidades } \\
\text { especiais }^{(16)}\end{array}$ & $\begin{array}{l}\text { Pesquisa descritiva com abordagem qualitativa } \\
\text { realizada em um hospital pediátrico, em quatro } \\
\text { unidades de saúde e no domicílio dos familiares de } \\
\text { crianças com necessidades especiais }\end{array}$ \\
\hline 12 & $\begin{array}{l}\text { Compreender o modelo de cuidado á criança na } \\
\text { atenção básica }^{(17)}\end{array}$ & $\begin{array}{l}\text { Pesquisa qualitativa embasada nos pressupostos } \\
\text { metodológicos da Grounded Theory }\end{array}$ \\
\hline 13 & $\begin{array}{l}\text { Avaliar a participação dos pais no cuidado à } \\
\text { criança }^{(18)}\end{array}$ & $\begin{array}{l}\text { Estudo exploratório com abordagem qualitativa, } \\
\text { realizado em serviços de pediatria de três instituições } \\
\text { portuguesas }\end{array}$ \\
\hline 14 & $\begin{array}{l}\text { Apreender as práticas do Cuidado Centrado } \\
\text { na Família (CCF) no cuidado do recém-nascido } \\
\text { hospitalizado que têm sido incorporadas pelos } \\
\text { enfermeiros }^{(19)}\end{array}$ & $\begin{array}{l}\text { Estudo descritivo de abordagem qualitativa, } \\
\text { desenvolvidonaUnidadedeCuidados Intermediários } \\
\text { e Unidade de Cuidados Intensivos neonatais de uma } \\
\text { maternidade pública de Belo Horizonte }\end{array}$ \\
\hline 15 & 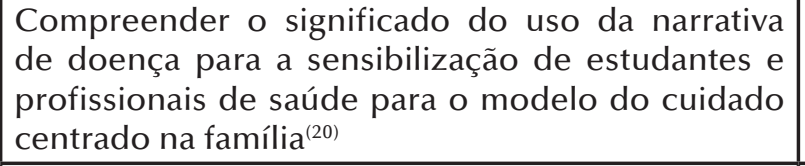 & $\begin{array}{l}\text { Estudo de abordagem qualitativa fundamentado no } \\
\text { modelo teórico do Cuidado Centrado na Família e na } \\
\text { Análise Qualitativa de Conteúdo, como referencial } \\
\text { metodológico }\end{array}$ \\
\hline 16 & $\begin{array}{l}\text { Apresentar as recomendações para o cuidado } \\
\text { aos pais de bebês internados em unidade de } \\
\text { terapia intensiva e o desenvolvimento de políticas } \\
\text { pautadas no cuidado centrado na família }{ }^{(21)}\end{array}$ & Revisão da literatura \\
\hline
\end{tabular}


Seis artigos (37\%) convergem no envolvimento dos familiares no cuidado à criança, a partir, do qual fortalece autonomia do familiar/acompanhante, reduzindo, posteriormente, a busca pelos serviços de saúde $^{(13,15-18,21)}$. Assim, oito (50\%) dos trabalhos coadunam no fortalecimento de políticas institucionais que enfatizam o reconhecimento da família como unidade cuidadora (1-2,10-11,16,19-21). $^{2}$

Além disso, três (19\%) dos artigos confluem para a utilização de modelos de cuidado à família e o empenho em desenvolver um instrumento com enfoque na família como pontos de partida para integralização do cuidado no ambiente hospitalar e domiciliar ${ }^{(14,17,20)}$. O encorajamento e o apoio aos familiares como elementos essenciais no processo saúde-doença e/ou promoção à saúde da criança também foram abordados por três (19\%) dos artigos ${ }^{(11,14,21)}$.

A indefinição de competências e habilidades dos enfermeiros, a ausência de padronização de instrumentos que avaliem a importância da família como unidade cuidadora foram temas em cinco

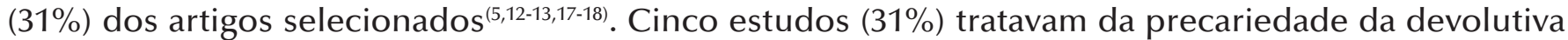
de informações, da ineficiência no momento do acolhimento e, bem como, no estabelecimento de vínculo entre o profissional e o familiar $(2,9,11,14,19)$. Nesta vertente, três $(19 \%)$ dos artigos identificaram que a inexistência ou efêmera infra-estrutura para o familiar/acompanhante esteve associada à falta de atendimento resolúvel e humanizado ${ }^{(2,10,12)}$.

Dois estudos (12\%) tratam das fragilidades que concernem na conturbada rotina hospitalar vivenciada pelo profissional, o que carreia em déficit de orientações no momento da alta hospitalar para o familiar/acompanhante, comprometendo o cuidado à criança ou, até mesmo, a tomada de decisões pelo familiar/cuidador ${ }^{(1,15)}$. E outros três $(19 \%)$ trazem a família como unidade de fiscalização do processo de trabalho da equipe de saúde ${ }^{(2,16,19)}$.

\section{DISCUSSÃO}

As categorias temáticas que emergiram foram: "Reconhecimento da unidade familiar" e "Limitações para o cuidado à criança com enfoque na família".

\section{Reconhecimento da Unidade Familiar}

O contexto familiar constitui o espaço inicial de reconhecimento e elucidação do processo de adoecimento de seus membros, sendo que o impacto da doença exerce influência em todos os integrantes da família, por meio dos relacionamentos e da própria dinâmica familiar ${ }^{(13)}$. Ressaltase que, frequentemente, os profissionais tendem a individualizar o cuidado, no caso o cuidado à criança, renunciando a dimensão familiar ${ }^{(6)}$. Sendo assim, os cuidados de enfermagem não podem ser desvinculados às necessidades da família, pois a própria interação familiar interfere na cura e no tratamento ${ }^{(4,21)}$.

Neste sentido, a família demonstra ser um elemento imprescindível no cuidado de seus membros, principalmente para os indivíduos que possuem maior dependência, como as crianças. Considerada como responsável por atender às necessidades biológicas, afetivas, sociais, econômicas de seus membros, ao ser dissociada deste, interfere diretamente nas condições de vida e saúde de seus $\operatorname{membros}^{(5,22)}$.

Portanto, a família deve ser inserida no cuidado, para além da divisão de tarefas com a equipe, e sim considerada como unidade de cuidado constante na vida da criança, para que participe do planejamento das ações de cuidado e tenha espaço para expressar seus problemas e necessidades ${ }^{(5,15,19)}$. Neste contexto, a equipe de enfermagem deve contribuir com a entrada do núcleo familiar para dentro da instituição ${ }^{(21)}$ e, até mesmo, inseri-lo no processo de cuidar da criança ${ }^{(6)}$.

A compreensão das necessidades de cada criança juntamente com as de sua família, assegura um tratamento menos traumático que reduz o sofrimento e contribui para a recuperação da criança ${ }^{(6,12)}$. O reconhecimento que a criança pertence a um núcleo familiar e envolve um contexto sociocultural, além da sua dinâmica familiar, permite a realização de um cuidado abrangente, flexível, efetivo e tangível à realidade de cada família, que exalta tanto a qualidade quanto a satisfação da assistência 
propiciada $^{(9-10,12)}$.

O profissional deve manter-se aberto e atento às interações familiares e às vivências de cada uma, respeitando valores e crenças, dificuldades e limites, além de demonstrar sempre presente e disponível para ouvir seus medos e dúvidas ${ }^{(15,19)}$. Para isso, é essencial o comprometimento, diálogo, reciprocidade e disponibilidade dos profissionais para acompanhar a família ${ }^{(1)}$.

Nesta perspectiva, a interação entre profissionais e familiares permite o reconhecimento da unidade familiar com trocas de saberes, com favorecimento de diálogo, o que torna possível a identificação de as fragilidades e potencialidades das capacidades de cada família para o cuidado ${ }^{(1,3,15,19,22)}$.

O cuidado à família requer envolvimento, respeito, ética, satisfação pessoal e estratégias de negociação dos profissionais de saúde ${ }^{(1,21)}$. Portanto, é desejável ter postura aberta às interações e vivências de cada família, reconhecendo sua individualidade, na pluralidade de relações que permeia este contexto interacional, e ter sensibilidade para compreender cada indivíduo. Nesta relação tornase possível a percepção dos elementos que envolvem o cuidado à família e à criança ${ }^{(2,6,9)}$.

Em relação ao cuidado com enfoque na família destaca-se, também, o incentivo à participação dos pais e o fortalecimento do vínculo com a criança ${ }^{(5,21,23)}$. O envolvimento da família no cuidado, articulado com os profissionais, favorece a qualidade deste ${ }^{(17,21)}$. Para tanto, ressalta-se que o reconhecimento dos aspectos que influenciam o processo de adoecimento e de hospitalização na família, incluindo suas necessidades, tem potencial para desencadear diferentes mecanismos de defesa para o enfrentamento do evento(14,22,24).Desta forma, o cuidado com enfoque na família é capaz de promover não somente a saúde e bem-estar da criança como também de todos os indivíduos da família ${ }^{(5,21,24)}$.

\section{Limitações para o cuidado à criança com enfoque na família}

O cuidado à família é considerado uma responsabilidade e compromisso moral da enfermagem, destarte, faz-se necessário o fortalecimento dos laços entre os profissionais enfermeiros e a família ${ }^{(1-2,5,19-20,23)}$. Para tanto é necessária uma definição institucional tornando explicito o cuidado à família na sua filosofia e na organização do serviço ${ }^{(5,14,21)}$.

A decisão institucional, em centrar o cuidado à família, demanda um ambiente adequado para que a estrutura familiar seja atendida em sua plenitude. Requer também suporte psicossocial, financeiro, pessoal e gerencial, além de, proporcionar educação e formação dos profissionais para estimular a comunicação efetiva entre estes e as famílias ${ }^{(5,14-15,21)}$.

Para a realização do cuidado com enfoque na família destaca-se a falta de instalações adequadas, profissionais pouco habilitados, falta de tempo para o cuidado de forma a contemplar as necessidades da família e não do indivíduo, inexistência de suporte e apoio gerencial, carência de políticas e diretrizes que o fundamentem o cuidado e a falta de formação e/ou educação continuada sobre a diversidade de culturas e crenças ${ }^{(11,13,17,21-22)}$.

A equipe de saúde encontra-se com dimensionamento ineficaz ou com pouco suporte teórico para a promoção do cuidado à família de crianças hospitalizadas. Nesse sentido, a execução errônea de procedimentos ou a negligência do cuidado à criança, inevitavelmente, serão reproduzidas pelo familiar/acompanhante. Haja vista que o enfermeiro é o profissional responsável pelas orientações ao familiar ${ }^{(1,9,22)}$.

Mediante os aspectos revisados, o cuidado à criança com enfoque na família traz em seu bojo a interação família/equipe, o que denota a complexidade do cuidado. Para tanto, são necessários esforços institucional e profissional, que se coadunem para desenvolvimento e instrumentalização de modelos de cuidado à família(12,21-22).

\section{CONSIDERAÇÕES FINAIS}

A produção do conhecimento expressa a necessidade de interação entre a família e o profissional/ equipe de saúde, e que esta seja respaldada por preceitos estabelecidos pelas instituições que prestam 
cuidado às crianças. De modo que a prática pautada no modelo biomédico e centrado na patologia, dê lugar a uma proposta que propicie a interação família-equipe que contemple o cuidado significativo e coerente às necessidades da criança e de seus familiares.

O cuidado à criança com enfoque na família, pode-se dizer, que tome a família como parceira, como protagonista do cuidado, valoriza a participação dos familiares na sua execução, favorece o vínculo profissional-família com reconhecimento do cuidado contínuo e evidencia as peculiaridades de cada família.

Faz-se necessário, portanto, fortalecer a construção de modelos teóricos que sustentem as práticas de cuidado à criança com enfoque na família, bem como analisar os aspectos institucionais que estimulam ou limitam este cuidado, para que se possam elaborar propostas que contribuam para o fortalecimento ontológico e epistemológico do cuidado à família.

\section{- REFERÊNCIAS}

1. de Souza TV,Oliveira ICS. Interação familiar/acompanhante e equipe de enfermagem no cuidado à criança hospitalizada: perspectivas para a enfermagem pediátrica. Esc. Anna Nery. [Internet] 2010;14(3) [acesso em 09 jul 2016]. Disponível:http://dx.doi.org/10.1590/S1414-81452010000300017.

2. de Sousa LD, Gomes GC, da Silva MRS, dos Santos CP, da Silva BT. A família na unidade de pediatria: percepções da equipe de enfermagem acerca da dimensão cuidadora. Cienc. enferm. [Internet] 2011;17(2) [acesso em 09jul 2016]. Disponível: http://dx.doi.org/10.4067/S0717-95532011000200010.

3. Woodgate RL,EdwardsM, Ripat J. How families of children with complex care needs participate in everyday life. Soc Sci Med.[Internet] 2012;75(10) [acesso em 12 dez 2014]. Disponível: http://dx.doi.org/10.1016/j. socscimed.2012.07.037.

4. Milbrath VM, de Siqueira HCH, da Motta MGC, Amestoy SC. Família da criança com paralisia cerebral: percepção sobre as orientações da equipe de saúde. Texto Contexto Enferm. [Internet] 2012;21(4) [acesso em 04 nov 2014]. Disponível:http://dx.doi.org/10.1590/S0104-07072012000400024.

5. Pinto JP, Ribeiro CA, Pettengill MM, Balieiro MMFG. Cuidado centrado na família e sua aplicação na enfermagem pediátrica. Rev. bras. enferm. [Internet] 2010;63(1) [acesso em 09jul 2016]. Disponível: http://dx.doi.org/10.1590/ S0034-71672010000100022.

6. de Azevedo ND, Collet N, Leite AIT, de Oliveira MRP, de Oliveira BRG. Cuidado de enfermagem a famílias de crianças hospitalizadas por doença crônica. Cienc Cuid Saude. [Internet] 2012;11(3) [acesso em 03 out 2014]. Disponível: http://dx.doi.org/10.4025/cienccuidsaude.v11i3.20260.

7. Ganong LH. Integrative reviews of nursing research. Res Nurs Health.[Internet] 1987;10(1) [acesso em 12 nov 2014]. Disponível: http://onlinelibrary.wiley.com/doi/10.1002/nur.4770100103/pdf.

8. Moher D, Liberati A, Tetzlaff J, Altman DG,PRISMA Group. Preferred reporting items for systematic reviews and meta-analyses: the PRISMA statement. Ann Intern Med. [Internet] 2009;151(4) [acesso em 12 out 2014]. Disponível: http://dx.doi.org/10.7326/0003-4819-151-4-200908180-00135.

9. de Lima AS, da Silva VKBA, Collet N, Reichert APS, de Oliveira BRG. Relações estabelecidas pelas enfermeiras com a família durante a hospitalização infantil. Texto Contexto Enferm. [Internet] 2010;19(4) [acesso em 09jul 2016]. Disponível:http://dx.doi.org/10.1590/S0104-07072010000400013.

10. Rossi CS, Rodrigues BMRD. Típico da ação do profissional de enfermagem quanto ao cuidado familial da criança hospitalizada. Acta paul. enferm. [Internet] 2010;23(5) [acesso em 09jul 2016]. Disponível: http://dx.doi. org/10.1590/S0103-21002010000500009.

11. Rocha RS, Lúcio IML, Lopes MMCO, Lima CRC, de Freitas ASF. Promoção do cuidado humanizado à família pela equipe de enfermagem na unidade neonatal. Rev. Rene. [Internet] 2011;12(3) [acesso em 10 out 2014]. Disponível: http://www.revistarene.ufc.br/revista/index.php/revista/article/view/255/pdf.

12. Murakami R, Campos CJG. Importância da relação interpessoal do enfermeiro com a família de crianças hospitalizadas. Rev. bras. enferm.[Internet] 2011;64(2) [acesso em 09jul 2016]. Disponível: http://dx.doi. 
org/10.1590/S0034-71672011000200006.

13. Apolinário MICG. Cuidados Centrados na Família: impacto da formação e de um manual de boas práticas em pediatria. Rev. Enf. Ref. [Internet] 2012;3(7) [acesso em 02 out 2014]. Disponível: http://www.scielo.mec.pt/pdf/ref/ vserIIIn7/serIIIn7a09.pdf.

14. Araya AA, Martínez AM, Badillo CM, Lema MP, Garay AS. Acompañamiento familiar en la hospitalización del usuario pediátrico de 6 a 12 años. Cienc. enferm. [Internet] 2012;18(1) [acesso em 09 out 2014]. Disponível: http:// dx.doi.org/10.4067/S0717-95532012000100007.

15. Barbosa MAM, Balieiro MMFG, Pettengill MAM. Cuidado centrado na família no contexto da criança com deficiência e sua família: uma análise reflexiva. Texto Contexto Enferm. [Internet] 2012;21(1) [acesso em 09 jul 2016]. Disponível:http://dx.doi.org/10.1590/S0104-07072012000100022.

16. de Moraes JRMM, Cabral IE. A rede social de crianças com necessidades especiais de saúde na (in)visibilidade do cuidado de enfermagem. Rev. Latino-Am. Enfermagem. [Internet] 2012;20(2) [acesso em 09 jul 2016]. Disponível: http://dx.doi.org/10.1590/S0104-11692012000200010.

17. de Sousa FGM, Erdmann AL. Qualificando o cuidado à criança na Atenção Primária de Saúde. Rev. bras. enferm. [Internet] 2012;65(5) [acesso em 09jul 2016]. Disponível: http://dx.doi.org/10.1590/S0034-71672012000500012.

18. de Melo EMOP, Ferreira PL, de Lima RAG, de Mello DF. Envolvimento dos pais nos cuidados de saúde de crianças hospitalizadas. Rev. Latino-Am. Enfermagem. [Internet] 2014;22(3) [acesso em 12 out 2014]. Disponível: http://dx.doi.org/10.1590/0104-1169.3308.2434.

19. Corrêa AR, de Andrade AC, Manzo BF, Couto DL, Duarte ED. As práticas do Cuidado Centrado na Família na perspectiva do enfermeiro da Unidade Neonatal. Esc. Anna Nery. [Internet] 2015;19(4) [acesso em 12 jun 2016]. Disponível: http://dx.doi.org/10.5935/1414-8145.20150084.

20. Amador DD, Marques FRB, Duarte AM, Balbino FS, Balieiro MMFG, Mandetta MA. Uso da narrativa como estratégia de sensibilização para o modelo do cuidado centrado na família. Rev Gaúcha Enferm. [Internet] 2015;36(1) [acesso em 11 jun 2016]. Disponível:http://seer.ufrgs.br/index.php/RevistaGauchadeEnfermagem/ article/view/46346.

21. Craig JW, Glick C, Phillips R, Hall SL, Smith J, Browne J. Recommendations for involving the family in developmental care of the NICU baby. J Perinatol. [Internet] 2015;35(Suppl 1) [acesso em 12 jun 2016]. Disponível: http://dx.doi.org/10.1038/jp.2015.142.

22. Pacheco STA, Rodrigues BMRD, Dionísio MCR, Machado ACC, Coutinho KAA, Gomes APR. Cuidado centrado na família: aplicação pela enfermagem no contexto da criança hospitalizada.Rev.enferm. UERJ. [Internet] 2013;21(1) [acesso em 12 out 2014]. Disponível: http://www.facenf.uerj.br/v21n1/v21n1a18.pdf.

23. Quirino DD, Collet N, Neves AFGB. Hospitalização infantil: concepções da enfermagem acerca da mãe acompanhante. Rev. Gaúcha Enferm. [Internet] 2010;31(2) [acesso em 12 out 2014]. Disponível:http://dx.doi. org/10.1590/S1983-14472010000200014.

24. dos Santos LM, Oliveira VM, de Santana RCB, Fonseca MCC, Neves ES, Santos MCS.Maternal experiences in the pediatric intensive care unit. R. pesq.: cuid. fundam. online. [Internet] 2013;5(1) [acesso em 12 out 2014]. Disponível: http://dx.doi.org/10.9789/2175-5361.2013.v5i1.3432-3442. 